\title{
BAÍA, SÉCULOS XVI-XVIII: POSSE, DISTRIBUIÇÃO E EXPLORAÇÃO DA TERRA, FRONTEIRA, FORMAS DE INCLUSÃO DO AMERÍNDIO
}

\author{
BAHIA, 16 ${ }^{\mathrm{TH}}-18^{\mathrm{TH}}$ CENTURIES: POSSESSION, DISTRIBUTION AND EXPLOITATION \\ OF LAND, BORDERS, INTEGRATION OF AMERINDIANS
}

Maria Leonor Garía da Cruz*

\begin{abstract}
RESUMO
Acompanhando o processo de colonização portuguesa da Baía e seu recôncavo nos primórdios da Época moderna, toda uma problemática ressalta de períodos de maior dinâmica: criação de capitania hereditária (1534) por documentos fundadores (carta de doação, foral e carta de sesmarias); estabelecimento de capitania régia com definição de sede de governo-geral do Brasil (regimento de Tomé de Sousa, 1548); elevação de territórios do Conde da Castanheira a nova capitania hereditária (1556, até incorporação na Coroa em 1754) e sua agregação a morgado do reino. Dessas transformações sociojurídicas ressaltam várias questôes: estratégia política, desenvolvimento da politica da graça régia, legislação e desvios na prática quotidiana, mecanismos de fixação de recursos humanos e de benefício das terras, sesmarias, estratégias catequéticas, transformação de fronteiras em zonas porosas, novas modalidades de captação e inclusão indígena. A pesquisa, embora de natureza histórica, utiliza conceitos e utensílios multidisciplinares, observando regimentos, epistolário, literatura e fontes inquisitoriais.
\end{abstract}

PALAVRAS-CHAVE: Colonização da Baía. Distribuição da terra. Inclusão indígena. Sesmarias.

\begin{abstract}
Several issues highlight the process of Portuguese colonisation of the Babia and its Reconcavo at the start of the modern age, in periods of greater dynamics: creation of hereditary captaincy (1534) by founding documents (letter of donation, foral and letter of sesmarias); establishment of royal captaincy with definition of headquarters of general government of Brazil (Tomé de Sousa regiment, 1548); raising the territories of the Conde da Castanheira to a new hereditary captaincy (1556, until its incorporation in the Crown in 1754) and its aggregation to morgado of the Kingdom. Important problems arise from these socio-legal transformations: political strategy, the policy of the royal grace, legislation and regular deviations, establishment of buman resources and distribution of the land, sesmarias, catechetical strategies, transformation of borders and porous areas, new ways to attract and include Amerindians. This historical research uses multidisciplinary concepts and tools observing regiments, letters, literature and inquisitorial sources.
\end{abstract}

KEYWORDS: Colonisation of Babia. Distribution of land. Amerindian integration. Sesmarias.

\footnotetext{
* Professora do Centro de História da Universidade de Lisboa. Investigadora Integrada do Centro de História da Universidade de Lisboa. Doutorado em História Moderna pela Universidade de Lisboa. Email: ml.garciacruz@gmail.com; cruzmaria@campus.ul.pt
} 


\section{CARACTERÍSTICAS DA EXPOSIÇÃO}

Apresentaremos nesta breve exposição interrogações e sínteses explicativas de fenómenos que acarretam a explanação de diferentes problemas, uns formulados e em estudo, outros quais pistas a aprofundar. Trata-se de uma pesquisa no âmbito da História mas que, naturalmente, se socorre também de formulações de questões, de conceitos e de metodologias de outras áreas disciplinares, seja o Direito, a Economia Política, a Filosofia, a Antropologia ou a Teoria da Residualidade, entre outras.

A partir de alterações jurídicas e redefinições no regime de propriedade e de exploração da terra na Baía de Todos os Santos, nas centúrias de quinhentos a setecentos, durante o processo de colonização portuguesa, com enfoque na importância das sesmarias, revisitaremos diferentes condicionantes da inclusão ameríndia durante esse processo, abordando temas como o sertão e novas fronteiras, a porosidade destas pelos variados contactos estabelecidos com o índio, a questão da posse da terra.

\section{DEFINIÇÕES E REDEFINIÇÕES SOCIOJURÍDICAS}

Sobre o processo de povoamento e de exploração territorial e económica da Baía, regularmente incrementado com a doação régia da respectiva capitania hereditária a Francisco Pereira Coutinho em 1534 e, após a dissolução desta, com a atribuição de uma nova capitania, agora régia, a Tomé de Sousa, em 1548, constituindo-se sede do governo geral do Brasil, devemos formular algumas questões de índole sociojurídica e política, económica, antropológica e cultural, que permitam compreender melhor a evolução nas suas vicissitudes históricas.

O povoamento e a exploração económica são incrementados através da carta de doação de D. João III e, da mesma forma que na distribuição de outras capitanias na época, através também da carta de foral e de sesmarias. Vivia-se em 1534 uma conjuntura de séria ameaça externa, em particular francesa, evidenciando-se a necessidade de uma fixação sistemática no Brasil da parte de Portugal e de uma divulgação dessas circunstâncias frente aos Estados europeus. Mais sensível e preciso se tornara, aliás, o conhecimento do litoral do território com as expedições costeiras ao tempo de Martim Afonso de Sousa, criando-se as devidas condições para concretizar a repartição régia de capitanias.

$\mathrm{Na}$ definição jurisdicional dos documentos fundadores de cada circunscrição, e nomeadamente da Baía, delimitavam-se territórios, a parte de exploração directa do capitão e a parte a redistribuir a foreiros, os privilégios de exploração económica, incluindo bens que no continente, eram ainda considerados Bens da Coroa como por exemplo águas, matas e florestas (CRUZ, 2001), percentagens de certos rendimentos devidas à Coroa, e ainda planeamento de cultivos, de instrumentos de defesa militar e de urbanização (CHORÃO, 1999).

Notoriamente tais instrumentos de domínio e de exploração, muito abrangentes, deixam transparecer o desconhecimento do sertão, das suas potencialidades económicas precisas e das gentes que o habitavam. Engenhos e explorações da época de Francisco Pereira Coutinho, bem como os povoadores, acabam, aliás, na Baía, por ser fustigados pelos ameríndios, nomeadamente os Tupinambás, 
que, em guerra, incluindo de emboscada, paralisam a colonização, destroem os frutos dela e, na sequência de uma tentativa de resgate pelo capitão, dão fim à vida deste na Ilha de Itaparica (1547).

O sucesso da exploração, embora temporário, terá sido confirmado ao fim dos anos estabelecidos pela carta de sesmarias, figura jurídica esta residual, herdada do Reino, da reforma agrícola fernandina, bem como das experiências atlânticas (SALDANHA, 2001). Sendo o objectivo povoar e retirar benefícios da terra, dependendo disso a continuação da posse da exploração, não admira que o rei acabasse com a capitania, afinal mal sucedida nos últimos anos. Tenha-se em conta especialmente a revolta ameríndia de 1545, testemunhada em fontes como Notícias do Brasil de Gabriel Soares de Sousa (SOUSA, 1989) e o Regimento de 1548 de Tomé de Sousa (MAGALHÃES; MIRANDA, 1999).

A transformação da capitania hereditária em proveito da Coroa não foi inteiramente pacífica pois considerou o filho do antigo capitão ter direito à herança e o rei, ganhando o processo em juízo, apenas lhe conceder uma soma reduzida como satisfação (GAVETAS II, p. 649-652). Tomé de Sousa será então, em 1548, o novo capitão da Baía, reformulada esta em capitania régia, e obrigar-se-á a todo um plano de pacificação do território (também de capitanias circundantes) e de redistribuição de sesmarias para atracção dos antigos povoadores refugiados na então chamada Vila Velha e noutras capitanias e, note-se, também de índios amigos. De recordar que restara fundamentalmente a comunidade em torno do português casado com uma índia, Diogo Álvares Correia, o Caramuru, cuja política com brancos e índios e descendência com casamentos mistos conduzirão, aliás, ao reforço das ligações com naturais e à pacificação e desenvovimento da colonização portuguesa.

A política do novo capitão, Tomé de Sousa, cujo destino seria fazer de S. Salvador uma cidadesede do governo geral, iria, assim, ser desenvolvida segundo coordenadas bem delineadas no seu Regimento régio, desde a militar à económica e ao relacionamento com os naturais, e coadjuvada de novas instâncias controladoras da Justiça (o Ouvidor geral) e da Fazenda (o Provedor-mor). Coordenarse-ía, ainda, com missões de Jesuítas que muito contribuiriam para a inclusão quanto possível do ameríndio.

\section{FRONTEIRAS POROSAS}

Poderemos talvez dizer que de uma fronteira estabelecida à base do conflito passa-se a uma fronteira porosa ao estabelecer-se contactos, embora controlados, com os ameríndios. Depois de uma época de execução dos rebeldes (escudada na figura da guerra justa e no regimento régio de 1548), e de convívio aberto com os ameríndios amigos em meio urbano, estabelece-se que caberia a cada capitão autorizar o contacto semanal com os naturais do sertão, atraindo-os ao comércio local, condicionado naturalmente pelas prescrições sobre mercadorias proibidas (CRUZ, 2017).

Em simultâneo, podemos acompanhar os esforços dos Jesuítas por alcançar uma nova fronteira, mediante autorização das autoridades locais, em regiões adentro do sertão onde pretendiam catequizar e, na concepção de Manuel da Nóbrega, fundar aldeias para albergar diversas tribos, conduzindo 
primeiro os naturais a submeter-se à lei e aos costumes portugueses, isto é, às autoridades locais, regionais, e ao Governador, para depois convertê-los (NÓBREGA, 1955; CRUZ, 2019a).

Apesar do continuado esforço das autoridades por impedir violência injustificada (a nível de leis, inclusive, conforme Amorim e Mendes (2010) e os Jesuítas acompanharem os debates contra a escravatura e pela definição do conceito de guerra justa, sabe-se por testemunhos documentais (regimentos, epistolário, depoimentos perante autoridades eclesiásticas e mesmo inquisitoriais durante a Visitação à Baía e seu recôncavo em 1591-92) como continuaram apresamentos ilegais de ameríndios e uma política criticável dos colonos que os colocavam ao seu serviço. Condenava Nóbrega inclusivamente (CRUZ, 2019a) a falta de atenção por parte desses colonos aos costumes e fé da mão-de-obra ameríndia que continuava, assim, a viver costumes ancestrais.

Claro que esta questão leva-nos a outras. Como e por quem se faziam as descidas? Nas fazendas e engenhos, os colonos praticam eles mesmos com rigor as normas da Igreja católica? As confissões da Baía durante a visitação inquisitoraial de Heitor Furtado de Mendonça indicam que não, na generalidade (VAINFAS, 1997). Senhores de engenho, fazendeiros e seus dependentes trabalhavam nos Domingos e dias santos, menosprezando esta e outras prescrições da prática católica. As tropas que se internavam no sertão, por sua vez, eram constituídas em parte e conduzidas por mamelucos, isto é, filhos de branco e índia.

\section{DUPLAS IDENTIDADES E HIBRIDISMOS}

Vale a pena deter-nos sobre esta figura do mameluco, presente em fontes portuguesas dos séculos XVI e XVII (GUEDES e GODOY, 2020), interrogando-nos, uma vez mais, sobre a inclusão do ameríndio, bem como a miscigenação, e, ao mesmo tempo, sobre a prevalência de duplas identidades no Brasil e mais particularmente, no caso em estudo, a Baía (CRUZ, 2021).

Sabe-se que nessas centúrias o mameluco, dada a sua dupla origem europeia e ameríndia, herdeiro de ambas as culturas, tornou-se um instrumento fundamental nas expedições para o interior, dados os seus conhecimentos de falas e, entre outros, também os medicinais.

As confissões de vários mamelucos durante a Visitação à Baía e seu recôncavo ao enviado do Conselho geral da Inquisição em 1591-92 (CRUZ, 2019b) revelam-nos indivíduos cristianizados e com profissões, por vezes casados, com mulher em zona urbana. As suas entradas no sertão (para descer os índios, por exemplo) manifestam, porém, a sua apetência por se mesclar facilmente com os ameríndios, para ganhar a sua confiança, participando do seu quotidiano com habilidade. Dançam, fumam, bebem, desnudam-se e pintam o corpo, juntam-se a várias mulheres, não guardam os preceitos da Igreja católica sobre domingos e dias santos ou o jejum de carne à sexta-feira. Há quem até salvaguarde na confissão que não comera carne humana mas sim de porco para disfarçar... Em contrapartida, revelam atitudes graves (testemunhando ou actuando), como a venda de armas para serem utilizadas contra os cristãos.

Seja como for, há outras circunstâncias agravadas que levam a atitudes próprias do comportamento dos naturais fora do mundo cristão, isto é, dos gentios. É o caso dos movimentos de 
culto, as santidades, que as autoridades pretendem coartar. Introduzem-se, assim, cristãos europeus e mamelucos no seio dessas comunidades, actuando da mesma forma que os gentios em torno de um ídolo e de artefactos parecidos com os dos cristãos (cruzes e contas) e seguindo rezas, danças e cantos. O objectivo será o de atrair e capturar a elite que dirige a santidade. Os meios, contudo, revelam a plasticidade dos indivíduos e, uma vez mais, uma porosidade entre o mundo cristão e o indígena.

Mas será que a santidade não é, por vezes, ela própria fruto de um hibridismo entre culturas diferentes? Veja-se a Santidade de Jaguaripe de 1585, na Baía, junto dos Tupinambá, e quanto o seu mentor terá aliado às gentilidades muito dos conhecimentos sobre doutrina e rituais adquiridos em aldeia jesuítica (VAINFAS, 2005).

O mameluco é, pois, uma identidade híbrida utilizada para a inclusão dos ameríndios no mundo católico. Embora de extrema utilidade para autoridades e colonos, não deixa de ser por vezes menosprezada na hierarquia social, à medida que avançamos na época moderna (KOK, 2004). A nível de correcções por parte da Igreja, por outro lado, parece ter havido uma certa complacência para com mamelucos e índios que não houve com os europeus ou filhos de reinóis. Isto embora as denúncias sobre mamelucos sejam mais abundantes que sobre ameríndios (RESENDE, 2019). Seja como for, são matérias e questões ainda em estudo e a aprofundar. Poderíamos falar de uma endoculturação, isto é, de uma assimilação do produzido culturalmente pelas condições prévias, circunstanciais, para utilizar um dos conceitos de Roberto Pontes na Teoria da Residualidade (PONTES, 2017)?

\section{REGIMES DE PROPRIEDADE E DE EXPLORAÇÃO DA TERRA}

Um outro grupo de problemas tem a ver com a exploração da terra e com orientações políticas. Regressamos de novo à questão das sesmarias e do seu carácter temporário e condicional para salientar como tal concessão pode tornar-se hereditária ou, com um desvio ainda maior da sua natureza primitiva, conectar-se com um morgado (CRUZ, 2014). O objectivo de origem é, naturalmente, o povoamento e a obtenção de benefícios na exploração de cultivos e de gado, a construção de engenhos, a procura de metais preciosos. Junta-se a defesa militar contra inimigos internos e externos, a urbanização.

A Baía e o seu recôncavo vai ser, como vimos, o enfoque para o estabelecimento de um governo geral com Tomé de Sousa. Também ele, como capitão, terá a seu cargo desde 1549 distribuir sesmarias. Ora anos depois, em 1552, um importante nobre conselheiro do rei e vedor da Fazenda real, D. António de Ataíde, Conde da Castanheira, provavelmente envolvido no processo de ocupação do território brasileiro desde a expedição exploratória de Martim Afonso de Sousa, seu primo, e a distribuição das primeiras capitanias, irá solicitar terras à entrada do recôncavo (terras no Rio Vermelho) e no interior deste duas ilhas centrais, uma pequena, a Ilha de Itamarandiba, e outra, bem maior, a Ilha de Itaparica. Parece-nos um pedido de estratégia política dado tratar-se de territórios indispensáveis à defesa de S. Salvador e do próprio recôncavo baiano, portanto, extremamente valorizadas.

Recebe tais territórios por doação e cartas de sesmarias. Todavia, e apesar de não fixar-se no Brasil, deixando em seu lugar um locotenente, levantando-se vozes por parte da Câmara contra o 
aumento de privilégios, Ataíde consegue a confirmação das doações e constituir-se com elas em capitão de uma capitania hereditária em 1556, isto graças a um acto de soberania régia que separava aquela da capitania régia.

D. António de Ataíde não fica por aí. No mesmo ano de 1556 solicita que tais terras constituídas em capitania fiquem ligadas a um morgado que ele já possui no Reino, instituído pela mãe, D. Violante de Távora. O herdeiro do morgado seria, assim, sempre capitão desses territórios no Brasil. De facto isso irá acontecer até ao século XVIII (1754, incorporação na Coroa). Estamos perante uma metamorfose política e jurisdicional que anula, naturalmente, o espírito das primitivas sesmarias, logo à partida pela dimensão territorial da capitania em causa, depois pelas regras de sucessão. O próprio Conde, porém, obriga-se à distribuição de aforamentos com objectivos similares (ANTT, MANUSCRITOS DA LIVRARIA 2597; CRUZ, 2014, p.105-108).

\section{SESMARIAS E INCLUSÃO AMERÍNDIA}

Uma questão que deixamos ficar aqui por último é ainda a das sesmarias, ligando a sua distribuição aos esforços por inclusão dos ameríndios, cruzamento de fenómenos nem sempre considerada nos estudos sobre a posse da terra (NOZOE, 2006).

Embora haja debate em pleno século XVI sobre os direitos territoriais dos índios, incluindo a nível ibérico, na verdade o enfoque refere-se ao sertão ou às aldeias fundadas pelos missionários. $\mathrm{O}$ objectivo na prática era descer os gentios do sertão e enquadrá-los em novo regime nas aldeias, garantindo a sua submissão política, ao mesmo tempo que se convertiam, e onde, inclusivamente a Corte (gratuitamente) e os colonos, como particulares, poderiam buscar mão-de-obra neste último caso assalariada (PERRONE-MOISÉS, 2000). Garantia-se, assim, a proximidade dos ameríndios, a sua cristianização e o seu sustento pela lavoura, ao conceder-lhes terras em sesmaria.

Com o tempo há suporte legal para as concessões serem feitas aos índios já cristãos, facto que contraria qualquer anterior noção dos gentios serem senhores das terras (sobretudo do sertão) ou o espírito dos requerimentos através do seu procurador. No Directório dos Índios pombalino (1757), todavia, confirma-se o texto de alguns documentos anteriores que consideravam os ameríndios os primários e naturais senhores das mesmas terras. Privilegiavam-se, contudo os descidos, convertidos e aldeados. Os resistentes à colonização, em contrapartida, caíam sob outra figura jurídica, a da guerra justa, perdendo a sua liberdade e propriedade de bens.

Deve salientar-se que o processo de colonização encobre simultaneamente situações complexas que se podem resolver dentro ou fora da lei. Que dizer da descida dos ameríndios do sertão para as aldeias e da situação jurídica das terras que ficavam sem dono? Ficariam devolutas e poderiam ser ocupadas legitimamente e redistribuída a sua ocupação por novos possidentes? O ameríndio perdia nessas circunstâncias, definitivamente, o direito de propriedade (BARROS, 2018).

Façamos referência, por fim, a um alvará de 1582, confirmado em 1652, e a provisões régias das centúrias de quinhentos e seiscentos, fundamentadas em documentos do século XVI, onde o Rei se 
dirige ao Governador e a Provedores para que se faça a restituição de terras doadas aos índios, entretanto sonegadas por colonos, no termo da Baía (DOCUMENTOS HISTÓRICOS, LXIV, p. 94-99). Ora a posse da terra irá basear-se precisamente nas cartas de sesmarias concedidas a ameríndios aldeados, verificando-se, pois, tratar-se de documentos de suma importância não só para o desenvolvimento económico mas também em termos políticos.

\section{REFLEXÕES FINAIS SOBRE PISTAS DE INVESTIGAÇÃO}

As sesmarias, figura jurídica residual com origem na legislação do reino, revelam-se fenómenos de suma importância no Brasil, tanto do ponto de vista demográfico e económico (povoamento e exploração da terra gerando benefícios), como político (definição de propriedade). Tal reflecte-se em todo o processo de colonização e, com particular interesse, na atracção e inclusão de ameríndios, não sem polémicas, como foi explanado.

Colocaram-se questões sobre continuidades e rupturas em casos particulares, nomeadamente a constituição na Baía de uma nova capitania hereditária emergente da capitania régia e que se vincula à sucessão de um morgado no reino. Persistem, todavia, aforamentos nos territórios do Conde da Castanheira e seus sucessores nas terras, assim como convénios com outros possidentes (Casa da Torre de Garcia d’Ávila) e com missionários. Importa vir a explorar tais pistas.

Muito importa, também, no processo da colonização portuguesa na Baía as relações com os naturais, relações essas nem sempre pacíficas e que envolvem o pouco conhecimento do sertão e mecanismos de inclusão, forçada ou não, condicionados por factores políticos, económicos e religiosos. Daí falarmos de fronteiras permeáveis ou porosas, fundadas não já na guerra mas também em processos de atracção pacífica do ameríndio, incluindo a distribuição de sesmarias.

Resulta de muitos dos fenómenos apontados uma mestiçagem cultural, fundamental para o prosseguimento da colonização portuguesa. Tal processo constrói-se, se não no todo, em grande parte, num espaço humano de características multiculturais tendente a constituir novas entidades sociais, prestigiadas ou não, conforme a evolução das mentalidades e das vicissitudes históricas que as condicionam.

\section{FONTES}

Arquivo Nacional da Torre do Tombo (ANTT), Manuscritos da Livraria 2597, Bens da Casa da Castanheira.

CHORÃO, M. J. B. (apres. transcr. paleográfica e notas). Doações e Forais das Capitanias do Brasil. 15341536, Lisboa, IAN-TT, s.d [1999].

DOCUMENTOS HISTÓRICOS, v. LXIV. Rio de Janeiro: Ministério da Educação e Saúde - Biblioteca Nacional (MES-BN), 1944, p. 94-99.

GAVETAS DA TORRE DO TOMBO. Lisboa, Centro de Estudos Históricos Ultramarinos (CEHU), T. I - XII, 1960-1977, V. II. 
MAGALHÃES, J. R.; MIRANDA, S. M. (org.). Regimento de Tomé de Sousa (17 Dezembro 1548. AHU, Códice 112, fols. 1-9). In: Tomé de Sousa e a Instituição do Governo Geral (1549): Documentos. Mare Liberum, n. 17, p. 13-26, Jun 1999.

NÓBREGA, M. Cartas do Brasil e mais escritos do P. Manuel da Nóbrega (Opera Omnia). Intr. notas S. Leite, por ordem da Universidade de Coimbra, 1955.

SOUSA, Gabriel Soares de. Notícia do Brasil, Lisboa: Alfa, 1989.

VAINFAS, R.. Confissões da Babia: Santo Ofício da Inquisição de Lisboa, Companhia das Letras, 1997.

\section{REFERÊNCIAS}

AMORIM, M. A.; MENDES, J. M. Questões Jurídicas sobre os Índios do Brasil. In:. CRISTÓVÃO (dir.). Cadernos de Literatura de Viagens N.2. Subsídios para o estudo dos índios das Américas. Lisboa: Almedina, 2010, p. 25-49.

BARROS, R. S. Protagonismo Indigena: arranjos e conflitos nas sesmarias dos jesuítas. Ilhéus: Editus; Edição do Kindle, 2018.

CRUZ, M. L. G. da. A Governacãa de D. João III: a Fazenda Real e os seus Vedores, Lisboa: Centro de História da Universidade de Lisboa, 2001.

CRUZ, M. L. G. da. Baía de Todos os Santos: Território de Fronteira. Coroa Portuguesa e Redes Familiares no povoamento e na relação com naturais e outros europeus. In: OLIVERO GUIDOBONO, S.; BENITO HIERRO, C. (coord.). Entre redes y espacios familiares en Ibero-américa. Repensando estrategias, mecanismos e idearios de supervivencia y movilidad, Sevilha: Egregius, 2017, p. 470-491.

CRUZ, M. L. G. da. Jesuítas e programas de acção na origem de concepções doutrinárias e de definições jurídicas no século XVI (Europa e América). Nomos. Revista do Programa de Pós-Graduação em Direito da Universidade Federal do Ceará, v. 39, n. 2, p. 253-274, jul-dez, 2019a.

CRUZ, M. L. G. da. Sedimentos culturais em construções quinhentistas, do teatro vicentino às visitações inquisitoriais ao Brasil. Decifrar, v. 7, n. 14, p. 55-73, 2019b.

CRUZ, M. L. G. da. Bens, direitos e rendimentos no Reino e na América portuguesa: o morgado e a capitania no século XVI. In: SERRÃO, J. V.; DIREITO, B.; RODRIGUES, E.; MIRANDA, S. M. (ed.). Property Rights, Land and Territory in the European Overseas Empires. Lisboa: CEHC; ISCTE-IUL, 2014. p. 99-114.

CRUZ, M. L. G. da. Baía nos séculos XVI-XVII, um universo de múltiplas (ou/e singulares) identidades: abordagem interdisciplinar. In: Identidades, segregación, vulnerabilidad. ¿Hacia la construcción de sociedades inclusivas? Un reto pluridisciplinar. Madrid: Dykinson., 2021. p. 118-135.

GUEDES, R.; GODOY, S.. Mamelucos (São Paulo y São Vicente, siglos XVI y XVII). Revista Historia y Justicia, v. 14, p. 1-28, 2020. Disponível em: http://journals.openedition.org/rhj/3706.

KOK, G. O sertão itinerante: expedições da capitania de São Paulo no século XVIII. São Paulo: Hucitec; Fapesp, 2004.

NOZOE, N. Sesmarias e apossamento de terras no Brasil colônia. Revista Economia v. 7, n. 3, p. 587$605,2006$. 
PERRONE-MOISÉS, B. Terras indígenas na legislação colonial. Revista da Faculdade de Direito da Universidade de São Paulo, v. 95, p. 107-120, 2000.

PONTES, R. A propósito dos conceitos fundamentais da teoria da residualidade. In: PONTES, R. et al (org.) Residualidade e Intemporalidade, Curitiba: CRV, 2017, p. 13-18.

RESENDE, M. L. C. "Da ignorância e rusticidade": os indígenas e a Inquisição na América portuguesa (séculos XVI-XIX). In: DOMINGUES, A.; RESENDE, M. L. C.; CARDIM, P. (ed.). Os indigenas e as justiças no mundo ibero-americano (sécs. XVI-XIX). Lisboa: CHUL, CHAM e PPGH/UFSJ, 2019, p. 87-126.

SALDANHA, A. V. de. As capitanias do Brasil. Antecedentes, desenvolvimento e extinção de um fenómeno atlântico. Lisboa: CNCDP, 2001.

VAINFAS, R. A Heresia dos Índios. Catolicismo e rebeldia no Brasil colonial. São Paulo: Companhia das Letras, 2005.

Data de submissão: 22/11/2021

Data de aprovação: 29/01/2022 